\title{
Increase in the Expression of a Family of Small Guanosine Triphosphate- Binding Proteins, Rab Proteins, during Induced Phagocyte Differentiation
}

\author{
Isabelle Maridonneau-Parini, ${ }^{*}$ Chen-Zhi Yang, Michel Bornens, ${ }^{\star}$ and Bruno Goud \\ *Centre National de la Recherche Scientifique, Centre de Génétique Moléculaire, 91190 Gif sur Yvette, France, \\ and Unité de Génétique Somatique (URA CNRS 361), Institut Pasteur, 75015 Paris, France
}

\begin{abstract}
Rab is a newly identified family of small G-proteins that share 35-70\% homology with the yeast Sec4p and Ypt1p involved in the regulation of the secretory pathway. Mature phagocytes display functions requiring organized intracellular traffic and, for this reason, we questioned whether phagocyte differentiation could correlate with the increased expression of rab proteins. Rabbit antisera raised against the recombinant proteins rab1 Ap, 2p, 4p, and 6p were able to detect the corresponding proteins in the human monoblast leukemic cell line U937. When these cells were induced to differentiate into monocyte/ macrophage-like cells displaying functional characteristics of a normal phagocyte, rab1 Ap, $2 p, 4 p$, and $6 p$ were increased and this correlated with an increase in the rab transcripts. Using a rab5 probe, we also observed an increased expression of the rab5 gene in differentiated cells. Similarly, differentiation of the human leukemic myeloblast HL60 cell line along either monocyte or granulocyte pathways induced an increased expression of the rab proteins. Rab proteins were also detected in human neutrophils and in guinea pig alveolar macrophages. As degranulation is one of the phagocyte functions acquired in the late stage of differentiation, we investigated whether rab proteins would be involved in this process. Although rab proteins were tightly membrane bound, none of them was detected in the specific or azurophil granules purified from human neutrophils. The increased expression of rab proteins in mature phagocytes suggests that they may promote functions highly developed in these cells. (J. Clin. Invest. 1991. 87:901-907.) Key words: granules - HL60 cells - neutrophils - small G-proteins • U937 cells
\end{abstract}

\section{Introduction}

Many of the so-called "small guanosine triphosphate (GTP)-binding proteins" have been recently identified $(1,2)$. Their molecular masses are in the $20-30-\mathrm{kD}$ region and they all possess consensus sequences for GTP binding and hydrolysis. Little is known about the specific functions of these proteins. However, some of them seem to be involved in the regulation of the intracellular traffic. In yeast, Ypt $1 p$ and Sec4p control two stages along the secretory pathway, between endoplasmic

Address reprint requests to Dr. Maridonneau-Parini, INSERM U332, Institut Cochin de Génétique Moléculaire, 22 rue Méchain, 75014 Paris, France. 1990

Received for publication 2 May 1990 and in revised form 16 August

J. Clin. Invest.

(C) The American Society for Clinical Investigation, Inc.

0021-9738/91/03/0901/07 \$2.00

Volume 87, March 1991, 901-907 reticulum and Golgi apparatus and between Golgi and the plasma membrane, respectively (3-5). Sec4p is located on the cytoplasmic face of both the plasma membrane and secretory vesicles in transit to the cell surface (4). Ypt $1 \mathrm{p}$ is present in the Golgi region (3). Among the mammalian small G-proteins already characterized, proteins from the rab family share 38$75 \%$ amino acid identity with Ypt $1 p$ and Sec4p (6). In addition, the domain corresponding to residues $35-40$, described in p21 ras as the effector-binding site, is highly conserved between rab proteins, Sec4p and Ypt $1 \mathrm{p} \mathrm{(6).} \mathrm{The} \mathrm{rab} \mathrm{family} \mathrm{is} \mathrm{the} \mathrm{only}$ example of mammalian small G-proteins possessing the effector domain homologous to Yptlp and Sec4p. Therefore, rab proteins could also be involved in intracellular traffic. With the exception of rab3p, which seems to be only present in nervous and endocrine cells (7-12), rab1 Ap, $2 p, 4 p, 5 p$, and $6 p$ appear to be ubiquitously distributed $(6,7)$.

Mature phagocytes are involved in different functions such as degranulation, phagolysosome formation, and directed locomotion that require organized intracellular traffic and sorting of granules and vesicles $(13,14)$. The involvement of small G-proteins in phagocyte traffic was suggested by the demonstration that, in permeabilized neutrophils, guanine nucleotides stimulate degranulation through a mechanism distinct from the stimulation of the "large G-proteins" involved in the transduction of activation signals across the plasma membrane (15). In addition, recent reports have described the presence of small G-proteins in phagocytes. One of them, possibly rap1, has been found associated with cytochrome b559 (16), a component of the superoxide-generating enzyme NADPH oxidase. Moreover, a novel class of ras-related proteins, racl and rac2, which are substrates for ADP ribosylation by botulinum toxin $\mathrm{C} 3$ ADP-ribosyltransferase, have been identified in leukemic myeloblasts (17). Most of the phagocyte activities require mobilization of intracellular proteins $(13,14)$, and these functions are acquired in the late stage of phagocytic differentiation. Therefore, we questioned whether this could correlate with the increased expression of proteins from the rab family. In the present study, the expression of rab proteins was compared between undifferentiated and differentiated phagocytes. The human monoblast-like cell line U937, obtained from a histiocytic lymphoma patient and the human leukemic cell line HL60, derived from a promyelocytic leukemia, have been widely studied as models for the understanding of the molecular events associated with phagocyte differentiation (18). In contrast to U937 which can only mature along the monocyte/ macrophage pathway, HL60 cells are characterized by a bimodal differentiation potency that can be induced to either granulocytic or monocytic maturation. The synthesis of rab proteins and the expression of their corresponding mRNAs were increased in HL60 or U937 cells induced to differentiate in phagocytes. We also report that, although rab proteins were found to be mostly membrane bound, they do not belong to phagocyte granules. 


\section{Methods}

\section{Cell isolation and cell culture}

Human neutrophils. Blood was collected from healthy donors and neutrophils were isolated after Dextran T-500 sedimentation and centrifugation through Ficoll-Hypaque as previously described (19). Residual erythrocytes were removed by hypotonic lysis, and neutrophils were resuspended in phosphate-buffered solution (PBS).

Alveolar macrophages. The trachea of anesthetized Hartley guineapigs was cannulated and macrophages were collected by repeated lung lavages with sterile PBS at $37^{\circ} \mathrm{C}$ as previously described (20).

HL60 and U937 cells. HL60 cells were kindly provided by Dr. Petit (Orsay, France) and U937 cells by Dr. Polla (Geneva, Switzerland). The cells were grown in suspension in RPMI 1640 supplemented with $10 \%$ heat-inactivated fetal calf serum (FCS) (Gibco Laboratories, Grand Island, NY), $100 \mathrm{U} / \mathrm{ml}$ penicillin, and $100 \mu \mathrm{g} / \mathrm{ml}$ streptomycin at $37^{\circ} \mathrm{C}$ in $5 \% \mathrm{CO}_{2}$ humidified atmosphere.

Maturation along the monocytic pathway was induced by exposing HL60 and U937 $\left(2-4 \times 10^{5}\right.$ cells $\left./ \mathrm{ml}\right)$ to $20 \mathrm{ng} / \mathrm{ml}$ phorbol myristate acetate (PMA) (Sigma Chemical Co., St Louis, MO) for $4 \mathrm{~d}$ in large-culture Petri dishes. Stock solution of PMA was $1 \mathrm{mg} / \mathrm{ml}$ in dimethyl sulfoxide (DMSO). At day 2, cultures were supplemented with fresh medium. At the end of the differentiation procedure, dishes were washed with warm $\mathrm{Ca}^{2+}$ and $\mathrm{Mg}^{2+}$-free PBS (supplemented with 0.5 $\mathrm{mM}$ PMSF, $3 \mu \mathrm{g} / \mathrm{ml}$ leupeptin, $0.6 \mathrm{U} / \mathrm{ml}$ aprotinin, $1 \mu \mathrm{g} / \mathrm{ml}$ pepstatin, and $0.5 \mathrm{mM}$ EDTA), and adherent cells were gently scraped with a rubber policeman. The cells were then collected by low-speed centrifugation and resuspended in warm PBS, pH 7.4, and cell viability was assessed by trypan blue exclusion ( $>85 \%$ ).

HL60 cells were also induced to differentiate in suspension along the granulocytic pathway by $6 \mathrm{~d}$ of exposure to $1.3 \% \mathrm{DMSO}$ (vol/vol), fresh medium being added at days 2 and 4 . The cells were then washed and resuspended in PBS; the cell viability was $>95 \%$.

\section{Superoxide generation}

U937 and HL60 cells exposed to PMA were cultured in 24-well plates. Floating cells were removed by washing the wells twice and $1 \mathrm{ml}$ of PBS containing $50 \mu \mathrm{M}$ nitroblue tetrazolium (NBT) ${ }^{1}$ was added. The cells were stimulated with $1 \mu \mathrm{M}$ A23187 (stock solution: $10^{-2} \mathrm{M}$ in DMSO) or with $25 \mu \mathrm{g} / \mathrm{ml} \mathrm{AA}$ at $37^{\circ} \mathrm{C}$. NBT-positive cells were counted $30 \mathrm{~min}$ after addition of the stimulating agent. A similar procedure was used with DMSO-differentiated HL60 except that they were stimulated in suspension, and NBT-positive cells were counted in a Malassez chamber.

In some experiments the NBT test was replaced by the superoxide dismutase (SOD)-inhibiting reduction of ferricytochrome $c(19)$, a more specific reaction to control the cell ability to generate $\mathrm{O}_{2}^{-}$. The same experimental procedure was used except that NBT was replaced by $80 \mu \mathrm{M}$ cytochrome $c$ with or without SOD. At the end of the stimulation period, the incubation medium was removed, centrifuged in order to eliminate any detached cells and the supernatants were measured at $550 \mathrm{~nm}$ in a double-beam spectrophotometer (Uvikon, Kontron, Switzerland) against the supernatants obtained from cells incubated in the presence of SOD (19). The same experiments were performed with undifferentiated cells.

\section{Cytometric analysis}

U937 and HL60 cells exposed to PMA were detached from flasks by scraping and prepared for DNA content analysis according to the method described by Vindelov (21). $0.25 \mathrm{ml}$ of cell suspension $\left(\sim 10^{7} / \mathrm{ml}\right)$ in Tris buffer $(100 \mathrm{mM} \mathrm{NaCl}, 100 \mathrm{mM}$ Tris, $\mathrm{pH} 7.6)$ was added to $2 \mathrm{ml}$ of ice-cold solution $\mathrm{A}(10 \mathrm{mM}$ glycine, $300 \mathrm{mM} \mathrm{NaCl}$, $0.1 \%$ Triton X-100, pH 10), $0.1 \mathrm{ml}$ boiled RNAse solution (1\%), and 50

1. Abbreviations used in this paper: GAPDH, glyceraldehyde 3-phosphate deshydrogenase; NBT, nitroblue tetrazolium; PMA, phorbol myristate acetate; SOD, superoxide dismutase. $\mu \mathrm{l}$ ethidium bromide solution $(0.2 \mathrm{mg} / \mathrm{ml})$. Tubes were inverted three times and kept at $4^{\circ} \mathrm{C}$. Relative DNA content was assayed on a flow cytometer (Epics V, Coulter Electronics, Inc., Hialeah, FL) using an argon laser (Spectra Physics Inc., Mountainview, CA) at $488 \mathrm{~nm}, 400$ $\mathrm{mW}$, and measuring the fluorescence above $590 \mathrm{~nm}$. Some experiments were performed by replacing ethidium bromide with Hoechst $33342(4 \mu \mathrm{g} / \mathrm{ml}$, final concentration) and using an argon laser at 351 $+364 \mathrm{~nm}$; the blue fluorescence of individual nuclei was assessed at a flow rate of 1,000 objects $\mathrm{s}^{-1}$ in a flow cytometer. Cell-cycle compartments were calculated from histograms using PARAl software (Coulter Electronics, Inc.) based upon an improved peak-reflect algorithm.

\section{Cell fractionation}

The method used has been described elsewhere (22). Briefly, neutrophils suspended in relaxation buffer $(100 \mathrm{mM} \mathrm{KCl}, 3 \mathrm{mM} \mathrm{NaCl}, 10$ mM Pipes, $3.5 \mathrm{mM} \mathrm{MgCl}_{2}$, and $1 \mathrm{mM}$ ATP, $\mathrm{pH} 7.3$ ) were cavitated at $375 \mathrm{psi}$ for $20 \mathrm{~min}$ in a nitrogen bomb at $4^{\circ} \mathrm{C}$ and collected in a tube containing EGTA (6 mM, final concentration), and the nondisrupted cells, the nuclei, and debris were removed by centrifugation at $400 \mathrm{~g}$ for 10 min at $4^{\circ} \mathrm{C}$. The supernatant was layered on a discontinuous Percoll gradient and centrifuged at $45,000 \mathrm{~g}$ for $20 \mathrm{~min}$ at $4^{\circ} \mathrm{C}$. Four fractions were obtained corresponding to the cytosol, cell membranes, and specific and azurophil granules. Each fraction was collected and centrifuged for $90 \mathrm{~min}$ at 245,000 $\mathrm{g}$ to remove the Percoll and, except for the cytosol, fractions were resuspended in $0.34 \mathrm{M}$ sucrose buffered with 10 $\mathrm{mM}$ Pipes at $\mathrm{pH}$ 7.0. Membranous and cytosolic fractions from U937 cells were obtained as described above except that nitrogen cavitation was performed at $250 \mathrm{psi}$ for $15 \mathrm{~min}$ at $4^{\circ} \mathrm{C}$.

\section{Immunoblot analysis}

Proteins from intact cells or subcellular fractions were dissolved in sodium dodecyl sulfate (SDS)-sample buffer, heated at $100^{\circ} \mathrm{C}$ for 10 min, separated on SDS-PAGE (12\% polyacrylamide slab gel) using the Mini-Protean II cell (Bio-Rad Laboratories, France) and transferred to nitrocellulose using the Multiphor II Novablot system as described by the supplier (LKB Produkter, Bromma, Sweden). After saturation with $1 \%$ gelatin, $0.5 \%$ bovine serum albumin (BSA) in $150 \mathrm{mM} \mathrm{NaCl}, 0.1 \%$

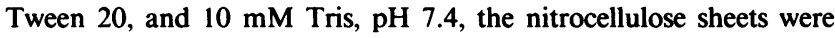
subsequently incubated with rabbit polyclonal antibodies (1:500 dilution) followed by incubation with ${ }^{125} \mathrm{I}$-protein $\mathrm{A}(0.1 \mu \mathrm{Ci} / \mathrm{ml})$ and were analyzed by autoradiography. Each gel lane was loaded with $25 \mu \mathrm{g}$ protein (the protein concentration was measured according to Bradford [23]) or with $50 \mathrm{ng}$ of recombinant rab proteins. The linear range of these assays has been monitored using recombinant rab proteins and was found to cover the range from 5 to $250 \mathrm{ng}$.

\section{Antibodies}

Polyclonal rabbit antibodies were generated against human rab proteins produced in Escherichia coli and purified to homogeneity by column chromatography as described by Zahraoui et al. (6). Rabl Ap has been coupled to keyhole limpet hemocyanin with glutaraldehyde (24). The immunization scheme was essentially as described by Louvard et al. (25).

\section{Northern blot analysis}

Total RNAs from undifferentiated and PMA-differentiated U937 cells were extracted with $4 \mathrm{M}$ guanidinium thiocyanate and purified by centrifugation through 5.7 M cesium chloride (26). The concentration of RNA was measured by absorbance at $260 \mathrm{~nm} ; 10 \mu \mathrm{g}$ RNA per well were electrophoresed in $1 \%$ agarose gels containing $2.2 \mathrm{M}$ formaldehyde and transferred to a nylon membrane (Hybond, Amersham, Bucks., UK) by the capillary blot method in $20 \times$ SSC $(1 \times$ SSC is $0.88 \%$ $\mathrm{NaCl}, 0.44 \%$ sodium citrate, $\mathrm{pH} 7$ ). The membrane was prehybridized at $42^{\circ} \mathrm{C}$ for $12 \mathrm{~h}$ in the hybridization buffer containing $50 \%$ deionized formamide, $6 \times$ SSPE $\left(5.2 \% \mathrm{NaCl}, 0.83 \% \mathrm{NaH}_{2} \mathrm{PO}_{4}, \mathrm{H}_{2} \mathrm{O}, 0.22 \%\right.$ EDTA, pH 7.2), $50 \mu \mathrm{g} / \mathrm{ml}$ each of BSA, Ficoll 400 (Sigma Chemical 


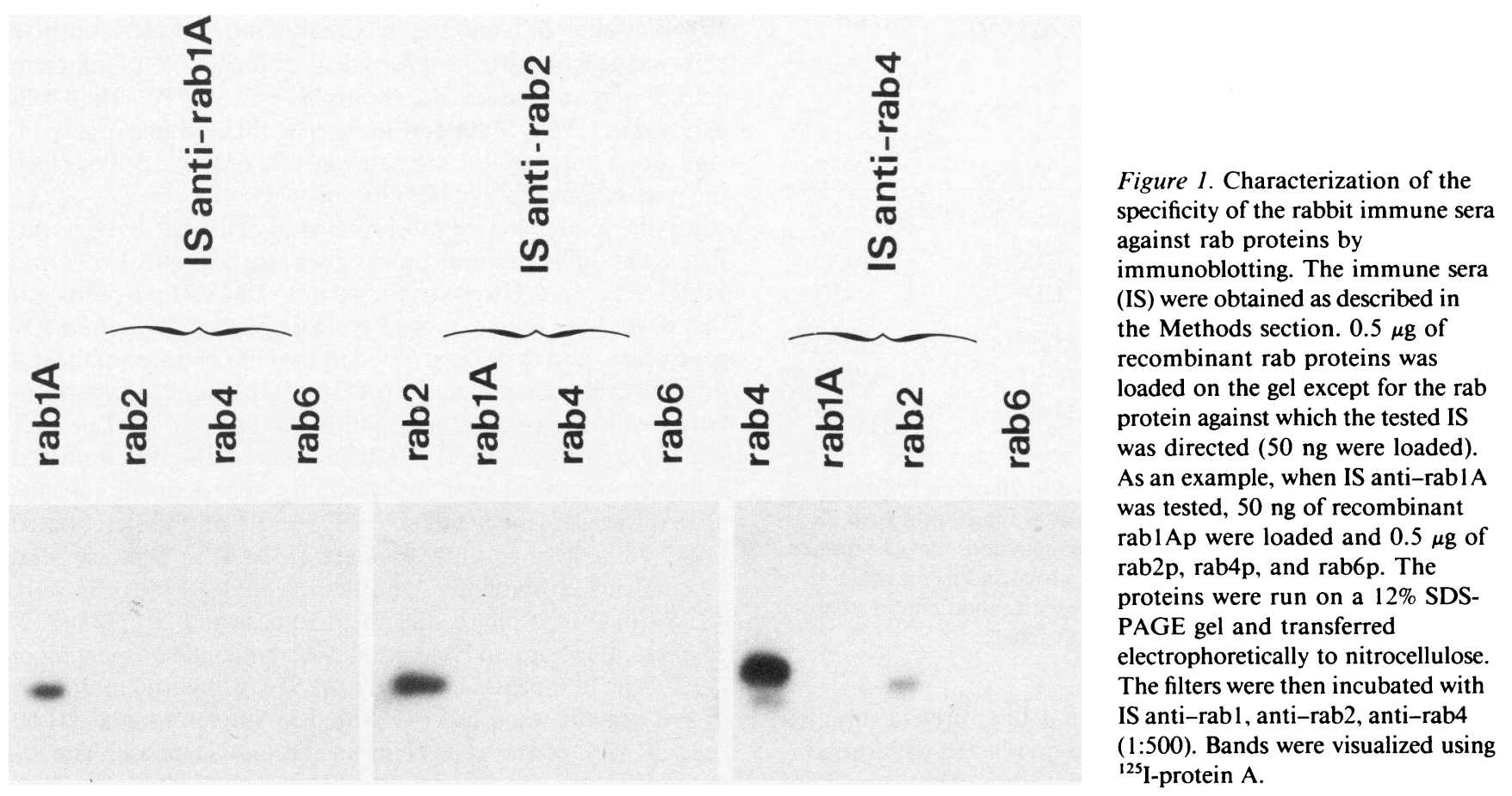

Co.) and polyvinylpyrrolidone, $0.5 \%$ SDS, and $100 \mu \mathrm{g} / \mathrm{ml}$ salmon sperm DNA. The membrane was then hybridized for $24 \mathrm{~h}$ with cDNA probes labeled with $\left[\alpha{ }^{32} \mathrm{P}\right] \mathrm{dCTP}\left(\mathrm{sp}\right.$ act, $\left.2 \times 10^{6} \mathrm{cpm} / \mathrm{ml}\right)$. The probe obtained from the rat rabl cDNA is the same as in Zahraoui (6). The following probes obtained from the rat rab cDNAs were used: rab2, a 900-pb EcoRI fragment containing $20 \mathrm{bp}$ of the 3 ' noncoding region and $50 \mathrm{bp}$ of the $5^{\prime}$ noncoding region; rab5, a $1.3 \mathrm{kbp}$ EcoRI-PUVII fragment containing $800 \mathrm{bp}$ from the $5^{\prime}$ noncoding domain. Rab6 probe, a EcoRI fragment containing $1.4 \mathrm{kbp}$ with $220 \mathrm{bp}$ from the $3^{\prime}$ and $550 \mathrm{bp}$ from the $5^{\prime}$ noncoding regions, was obtained from the human rab cDNA. After hybridization, the membranes were washed twice at room temperature for $15 \mathrm{~min}$ in $2 \times$ SSC supplemented with $0.1 \%$ SDS and once for $60 \mathrm{~min}$ at $65^{\circ} \mathrm{C}$ in $0.5 \times \mathrm{SSC}$ supplemented with $0.1 \%$ SDS. The membranes were then exposed to a hyperfilm-MP (Amersham) at $-80^{\circ} \mathrm{C}$. Glyceraldehyde 3-phosphate dehydrogenase (GAPDH) mRNA levels were used as an internal standard using the probe described elsewhere (27). The signals obtained by densitometric scanning of autoradiograms were integrated using the VISILOG software (Noesis, France).

\section{Results}

Presence of rab proteins in alveolar macrophages and neutrophils. Using polyclonal antibodies, we have analyzed the expression of rab proteins in guinea pig alveolar macrophages and human neutrophils. In that the members of the rab family share $30-45 \%$ amino acid identity (the region of best homology being the domain involved in GTP binding/hydrolysis) (6), we first tested the specificity of the immune sera generated against each of the purified rab proteins expressed in E. coli. As shown in Fig. 1, antisera against rabl $\mathrm{Ap}$ and $\mathrm{rab} 2 \mathrm{p}$ recognized only rabl Ap and rab2p respectively. The monospecificity of the antiserum anti-rab6p has been reported elsewhere (28). Antiserum against rab5p was not specific enough to be used. Antiserum against rab4 $p$ faintly recognized purified rab2 $p$. However, in cell lysates, no signal was detected at the migration position of rab2p (Fig. 2) with anti-rab4p antiserum probably because the level of endogenous rab $2 p$ was low compared to the amount of recombinant rab2p $(0.5 \mu \mathrm{g})$ applied to the gel in Fig. 1. In addition, none of the antisera recognized purified Sec4p or p21 ras (data not shown), further indicating that the antibodies were not directed against the highly conserved GTP binding/hydrolysis domains common to the rab and the other ras-related proteins.

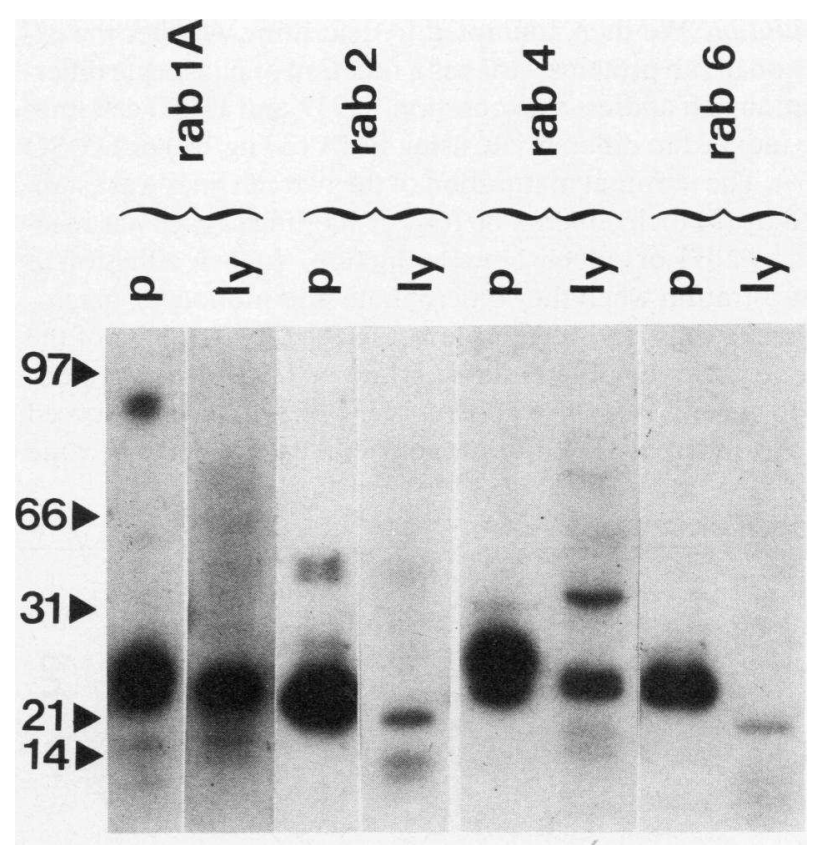

Figure 2. Immunoblot analysis of rab proteins in guinea pig alveolar macrophages. Recombinant rabl Ap, rab2p, rab4p, and rab6p (50 ng) $(p)$ and proteins $(25 \mu \mathrm{g} /$ well) from total cell lysates $(l y)$ were separated on a $12 \%$ polyacrylamide-SDS gel, transferred to nitrocellulose, and probed with immune sera against rab1Ap, rab2p, rab4p, and rab6p respectively as in the legend of Fig. 1. Molecular weight standards are shown on the left $\left(\times 10^{-3}\right)$. 
Table I. Generation of $\mathrm{O}_{2}^{-}$by Differentiated U937 and HL60 Cells

\begin{tabular}{llcc}
\hline & & \multicolumn{2}{c}{$\mathrm{O}_{2}^{-}$} \\
\cline { 3 - 4 } Cell line & $\begin{array}{c}\text { Differentiating } \\
\text { agent }\end{array}$ & \multicolumn{2}{c}{ Amol/10 cells } \\
& & A23187 \\
U937 & None & UD & UD \\
HL60 & None & UD & UD \\
U937 & PMA & $5.81 \pm 1.28$ & $7.23 \pm 1.07$ \\
HL60 & PMA & $2.78 \pm 0.72$ & $0.37 \pm 0.09$ \\
HL60 & DMSO & $2.11 \pm 0.93$ & ND \\
& & &
\end{tabular}

U937 and HL60 cells were exposed for $4 \mathrm{~d}$ to $20 \mathrm{ng} / \mathrm{ml}$ PMA or for 6 d to $1.3 \%$ DMSO. The cells were stimulated for 20 min with 25 $\mu \mathrm{g} / \mathrm{ml} \mathrm{AA}$ or with $1 \mu \mathrm{M} \mathrm{A} 23187$ and the reduction of cytochrome $c$ was measured in the presence (reference cuve) and in the absence (sample cuve) of SOD in a double-beam spectrophotometer. Abbreviations: ND, not determined; UD, undetectable.

Western blot analysis showed that the antisera directed against rab1 Ap, rab2p, rab4p, and rab6p reacted with proteins from total macrophage lysates (Fig. 2). It should be pointed out that the endogenous rab proteins, especially rab6p, migrated slightly faster on SDS-PAGE than the corresponding proteins produced in $E$. coli, suggesting that posttranslational modifications may occur in mammalian cells. In addition, the minor bands detected by the immune sera were also detected by the preimmune sera (data not shown). Immunoblots performed with lysates from human neutrophils gave results similar to alveolar macrophages (data not shown).

Expression of rab proteins during induced myeloid cell differentiation. We then attempted to determine whether the expression of rab proteins varies as a function of phagocyte differentiation. To address this question, U937 and HL60 cell lines were induced to differentiate using PMA $(20 \mathrm{ng} / \mathrm{ml})$ or DMSO (1.3\%). The terminal maturation of the two cell lines was established by $(a)$ their superoxide $\left(\mathrm{O}_{2}^{-}\right)$generating capacity as measured by NBT or cytochrome $c$ reduction, $(b)$ their adhesion to the substratum when they differentiate into monocyte, macrophage-like cells, and $(c)$ their arrest in the $\mathrm{G} 0-\mathrm{G} 1$ phase of the division cycle. Undifferentiated HL60 or U937 cells were unable to generate $\mathrm{O}_{2}^{-}$or to adhere. U937 or HL60 cells exposed to PMA differentiated into monocyte-like cells. They became adherent after $24 \mathrm{~h}$ and the maximal number of NBT-positive cells was reached after $2 \mathrm{~d}$ for U937 cells $(91 \pm 5 \%$ of adherent cells, $n=5)$ and $3 \mathrm{~d}$ for HL60 cells $(87 \pm 6 \%, n=3)$. HL60 cells exposed to $1.3 \%$ DMSO were induced to differentiate in suspension along the granulocytic pathway and required $5 \mathrm{~d}$ to reach the maximal number of NBT-positive cells $(78 \pm 6 \%, n=3)$. To study the expression of rab proteins in cells that have terminated the differentiation process, we worked with U937 and HL60 cells exposed to PMA for $4 \mathrm{~d}$ or to DMSO for $6 \mathrm{~d}$, since at this stage, they fully express a typical phagocyte function $\left(\mathrm{O}_{2}^{-}\right.$ generation) and they are arrested in the G0-G1 phase of the cell division cycle. The generation of $\mathrm{O}_{2}^{-}$was measured upon stimulation with the calcium ionophore A23187 $\left(10^{-5} \mathrm{M}\right)$ or with AA $(25 \mu \mathrm{g} / \mathrm{ml})$ (Table I). Undifferentiated and differentiated cells were analyzed by flow cytometry. The following results are expressed as mean $\pm \mathrm{SD}, n=3: 53 \pm 7 \%$ of undifferentiated U937 cells were in G0-G1 phase, $35 \pm 6 \%$ in $S$ phase, and $12 \pm 3 \%$ in G2-M phase. Undifferentiated HL60 cells were $48 \pm 6 \%$ in G0-G1 phase, $32 \pm 5 \%$ in S phase and $20 \pm 5 \%$ in G2$\mathrm{M}$ phase. Exposure to PMA for $4 \mathrm{~d}$ increased the proportion of U937 cells in the G0-G1 phase $(92 \pm 5 \%)$. Similarly, inhibition of cell growth was observed with PMA-differentiated HL60 cells, $91 \pm 4 \%$ of the cells being in the G0-G1 phase. The remaining $8-9 \%$ corresponded to bi- or polynucleated cells as observed by optical microscopy.

When equal amounts of total proteins from undifferentiated and PMA- or DMSO-differentiated HL60 cells were loaded (Fig. 3), we observed that rabl Ap, $2 p, 4 p$, and $6 p$ were expressed in nondifferentiated cells but their amounts were higher in mature cells. A similar increase in the expression of rab proteins was detected in lysates from U937 cells induced to differentiate with PMA (Fig. 3). In undifferentiated U937 cells, rab6p was detectable after a longer time exposure of the X-ray film.

As the small GTP-binding proteins appear to exist in both membrane-bound and soluble forms (29), we investigated the immunoreactive signals in the membrane and cytosol fractions prepared from mature and immature U937 cells. The signal was higher in the membrane fraction from PMA-treated cells than in undifferentiated progenitor cells (Fig. 4). Rabl Ap and rab6p were weakly detected in the cytosol fraction (Fig. 4). These results indicate that the increased amounts of rab proteins in mature phagocytes accumulate in the membrane fraction and not in the cytosol. Rabl Ap, $2 \mathrm{p}, 4 \mathrm{p}$, and $6 \mathrm{p}$ are tightly bound to the membrane since treatment of the membranes

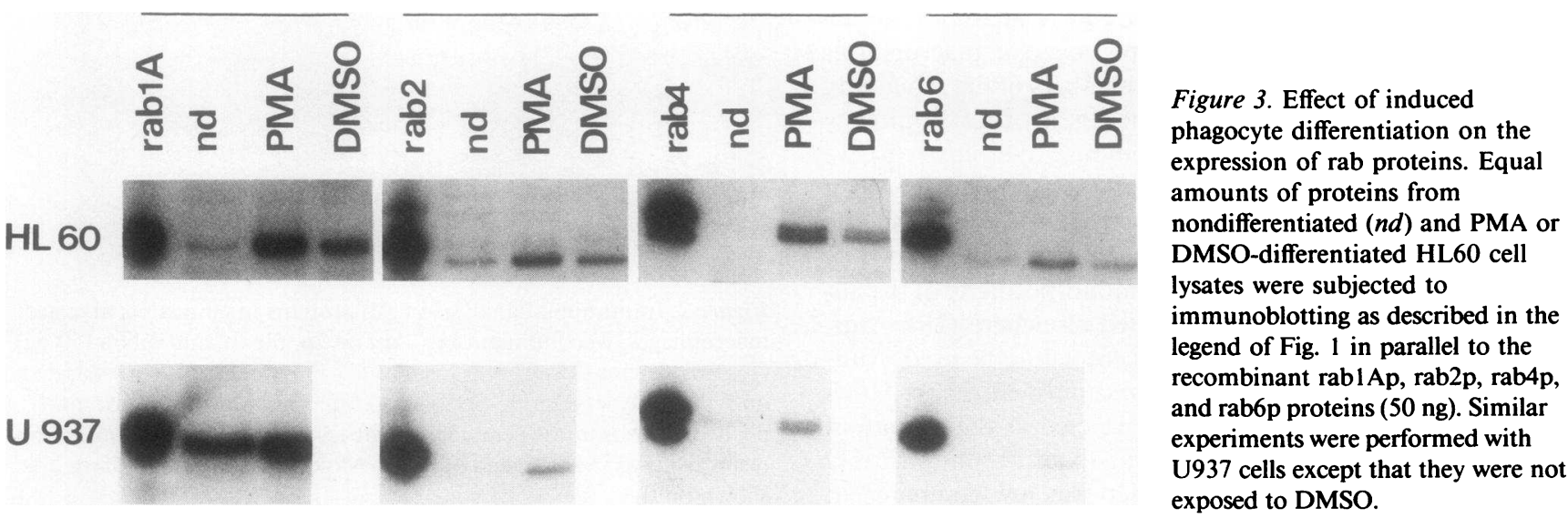




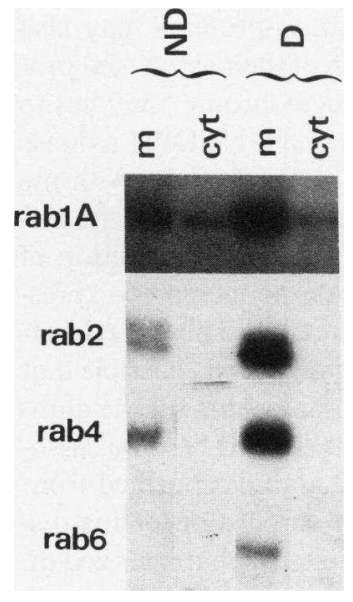

Figure 4. Distribution of rab proteins between the cytosol and membrane fractions in nondifferentiated U937 cells $(N D)$ and PMA-induced U937 cell differentiation $(D)$. Cell cavitation was performed in a nitrogen bomb. Cell membranes $(m)$ and cytosol $(c y t)$ were separated by density centrifugation on a Percoll gradient as described in the Methods section. The proteins $(25 \mu \mathrm{g} /$ well $)$ were immunoblotted using immune sera against rablAp, $2 p, 4 p$, and $6 p$.

with the chaotropic agent urea $(6 \mathrm{M})$, or with $0.2 \mathrm{M}$ sodium carbonate ( $\mathrm{pH} \mathrm{11}$ ), or high salt concentration $(1 \mathrm{M} \mathrm{NaCl})$ did not induce the dissociation of rab proteins. However, membrane exposure to $1 \%$ Triton $\mathrm{X}-100$ for 2 min at $4^{\circ} \mathrm{C}$ fully solubilized the rab proteins (data not shown).

The accumulation of rab proteins in the differentiated cells could be the result of changes at the transcriptional or translational levels. In PMA-differentiated U937 cells, the level of rabl, 2, 5, and 6 mRNAs increased greatly (Fig. 5). Rab4 probe gave nonspecific bands making it useless in this study (data not shown). As observed in human fibroblasts (6), rabl cDNA probe revealed two transcripts, rab2 probe detected three mRNAs, and rab5 and rab6 were each expressed as a single
mRNA (Fig. 5). We verified that the amount of transferred mRNA did not vary significantly between the nondifferentiated and the differentiated cells using the GAPDH probe (Fig. 5). To evaluate the relative increase in rab transcripts in differentiated cells, densitometric scans of Northern blots were performed. The relative level of the low molecular weight transcript of rab1 was increased 3.8-fold in differentiated cells, the second transcript was increased 2.2-fold. Rab2 mRNAs were increased 1.9-, 3.7-, and 3.0-fold for the low, intermediate, and high molecular weight transcripts, respectively. Rab5 mRNA was increased 10.1 -fold and rab6 mRNA 2.6-fold. These results suggest that the increase in rab proteins in mature phagocytes is regulated at the transcriptional level.

Rablp, $2 p, 4 p$, and $6 p$ are not associated with neutrophil granules. One of the main characteristics of phagocyte differentiation is the accumulation of secretory granules and the development of fully active stimulus-secretion coupling mechanisms. We wondered whether rab proteins might be located on granules and, therefore, involved in the control of regulated secretion. Since induced maturation of HL60 cells fails to develop specific granules (18), we decided to investigate whether rab proteins would be located at the granule level in human neutrophils. Using a preparation that provides a high level of purification of specific and azurophil granules (22), we observed that none of the antisera against rab proteins reacted with both granule types (Fig. 6) obtained from different blood donors. Rabl Ap, $2 p, 4 p$, and $6 p$ appeared to accumulate in the membrane fraction, a weak signal being detected in the cytosol with the four antisera. It should be pointed out that two additional bands migrating more slowly than rab2p were also detected with the antiserum in the membrane fraction from hu-

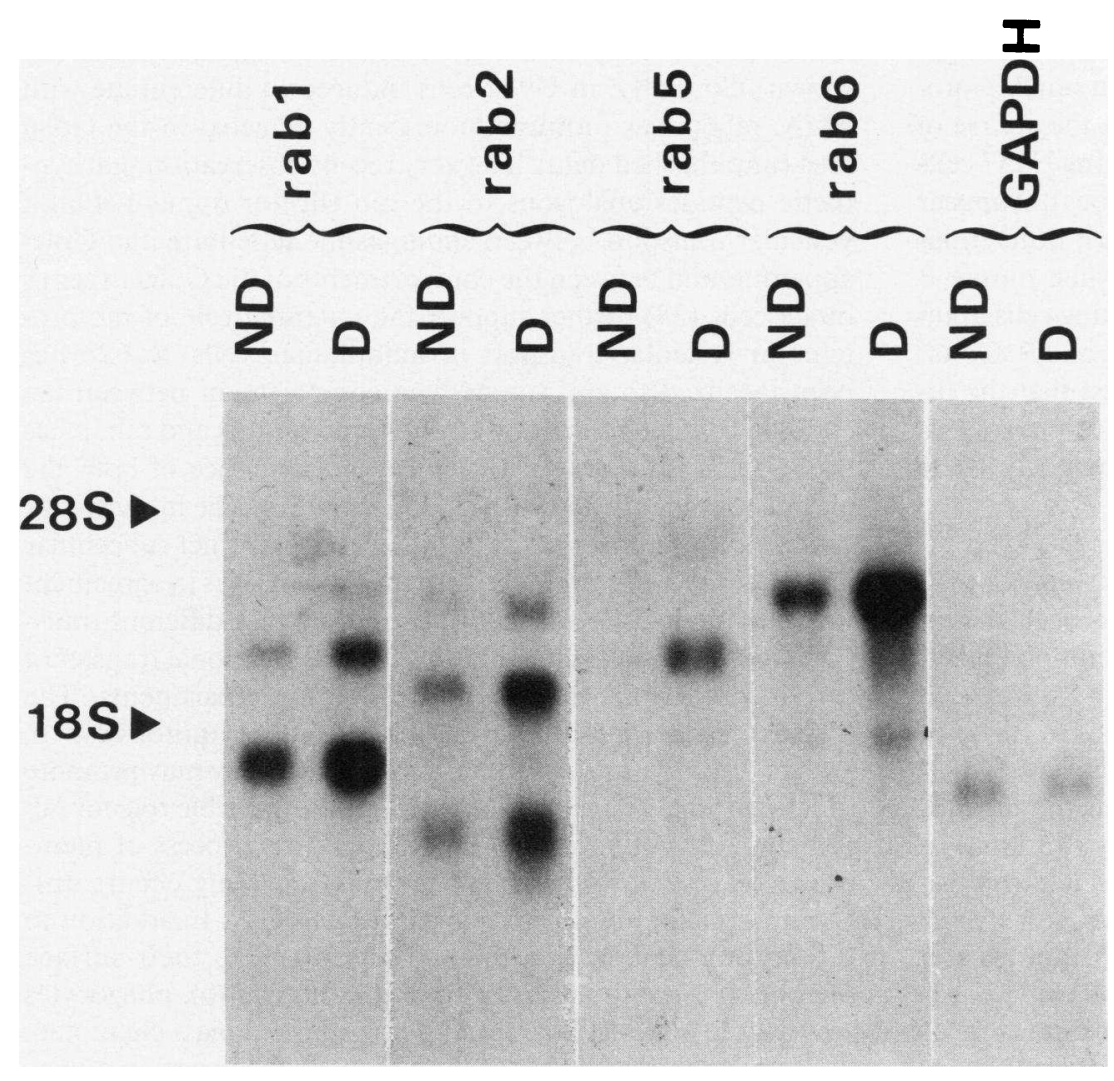

Figure 5. mRNA expression of the rab genes in nondifferentiated $(N D)$ and PMA-differentiated U937 cells $(D)$. Total RNAs from nondifferentiated cells and from cells induced to differentiate by 4-d exposure to PMA were electrophoresed (10 $\mu \mathrm{g}$ per well), blotted to a nylon membrane, and hybridized with rab1, rab2, rab5, rab6, and GAPDH probes as described in the Methods section. The membranes hybridized with the rab probes were subjected to autoradiography at $-80^{\circ} \mathrm{C}$ for 16 $\mathrm{h}$ and the membranes hybridized with GAPDH probe were exposed for $30 \mathrm{~min}$. Positions of $28 \mathrm{~S}$ and $18 \mathrm{~S}$ ribosomal RNAs are indicated on the left. 
Figure 6. Distribution of rab proteins between cytosol, membrane, and specific and azurophil granules from human neutrophils. Postnuclear supernatant from disrupted human neutrophils was fractionated by density centrifugation on a discontinuous Percoll gradient as described in Methods. Proteins from each fraction ( $25 \mu \mathrm{g}$ per well) were immunoblotted with immune sera against rablAp, rab2p, rab4p, and rab6p.

man neutrophils (Fig. 6). These bands were not observed in U937 and HL60 cells; we do not know at present what they represent.

\section{Discussion}

In this article we report that rab mRNAs and rab proteins are more highly expressed in mature phagocytes than in their progenitor cells. The proteins are found in both a membrane-associated and cytosolic form in undifferentiated and differentiated cells, the membrane-bound form being predominant before and after phagocyte differentiation. This induction of the expression of rab proteins in myeloid cells acquiring the phenotype of phagocytes was observed using either PMA or DMSO, suggesting that this induction is more likely to represent a step in the differentiation program than a pharmacological effect of the differentiating agent. The increase in the expression of small G-proteins is not a general feature associated with phagocyte differentiation since transcripts from racla (a small G-protein $\mathrm{C} 3$ botulinum toxin substrate) increased in the course of HL60 cell differentiation and decreased in maturing U937 cells (17). In addition, the increase in rab expression does not appear to be a general phenomenon associated with cell differentiation. Indeed, rab transcripts are not increased when mouse B lymphocytes differentiate in vitro into IgG-secreting cells upon stimulation with lipopolysaccharides (C. Z. Yang and B. Goud, manuscript in preparation). These results suggest that the increased expression of rab proteins in differentiated phagocytes may be associated with functions highly developed in these cells.

The presence of some other small G-proteins has been recently described in phagocytes. In human neutrophils, a protein from the ras superfamily, possibly rap-1, has been shown to be associated with cytochrome b559 (16), a component of the $\mathrm{O}_{2}^{-}$-generating enzyme NADPH oxidase. In addition, two nonidentified small $G$-proteins have been described to copurify with the membrane receptor to the chemotactic agent FMLP from differentiated HL60 cells (30). It is interesting to note that cytochrome b559 and FMLP receptor are poorly expressed in undifferentiated phagocytes $(18,31)$. In mature neutrophils, both cytochrome b559 and FMLP receptor are, for a part, stored in the specific granules and are translocated to the plasma membrane during the degranulation process $(22,32$, 33). This suggests that, in parallel to the increased expression of cytochrome b559 and the chemotactic receptor along phago- cyte maturation, their associated small G-proteins may also increase and control either the insertion of their associated proteins into the plasma membrane (i.e., cytochrome b559 has to be at the end of the electron transport chain NADPH oxidase [34]) or to participate into the fusion of the granules with the plasma membrane upon phagocyte activation. Phagocyte differentiation appears to correlate with both the acquisition of degranulation capacity $(13,18)$ and with the increased expression of rab proteins (this work) which are candidates for participating in the intracellular traffic. Therefore, it was possible that one (or more) of the rab proteins may be located on the granules. However, none of the rab proteins studied here was associated with either specific or azurophil granules purified from human neutrophils. This suggests that small G-proteins distinct from rab proteins probably remain to be characterized on specific and azurophil granule membranes.

At present, none of the physiological functions of the rab proteins has been precisely determined in mammalian cells. Since they share high homology with Sec4p and Yptlp, it is likely that they participate in the regulation of intracellular traffic. This hypothesis is sustained by the results recently obtained by several laboratories on the subcellular localization of rab proteins. RablAp, which is the mammalian homologue of Yptlp $(6,35)$, a protein apparently required for protein transport from endoplasmic reticulum to Golgi complex (36), is probably associated with the Golgi apparatus (3, B. Goud and N. Touchot, unpublished observation). Rab6p has been found to be associated with the surface of Golgi cisternae, probably medial and trans, in a wide variety of animal cells (28). Rabl Ap and rab6p are probably associated to the Golgi apparatus in human neutrophils since Golgi membranes were present in the membrane fraction obtained by centrifugation on Percoll gradient (37) as demonstrated by galactosyl transferase (a specific Golgi marker) immunoreactivity using an antiserum kindly provided by E. Berger (Zurich, Switzerland; data not shown). Similarly, in U937 cells induced to differentiate with PMA, rab6p was immunofluorescently detected in the Golgi area (unpublished data). The very recent observation that synthetic peptides analogous to the rab effector domain inhibit vesicular transport between endoplasmic reticulum and Golgi apparatus and between the compartments of the Golgi in semiintact cells (38) further support the potential role of rab proteins in vesicular transport in mammalian cells. Rab2p has been localized to an intermediate compartment between the endoplasmic reticulum and the Golgi apparatus and rab5p has been found associated with the cytoplasmic face of both the plasma membrane and early endosomes (39). The intracellular localization of rab4 $p$ is still unknown. The distinct subcellular localizations of the proteins from the rab family is in agreement with the model of Bourne (29) proposing that different transport small G-proteins may ensure the unidirectional transfer of carrier vesicles between two subcellular compartments. The high expression in mature phagocytes of the ubiquitous rablp, $2 \mathrm{p}, 4 \mathrm{p}, 6 \mathrm{p}$, and probably rab5p suggests that they may promote functions highly developed in these cells. A possible role for rab proteins would be their involvement in the process of membrane recycling. Ordinary membrane recycling occurs uniformly over the surface of nonmotile cells (14). In addition to the finding that resting macrophages recycle their surface membrane four times faster than fibroblasts (40), phagocytes are capable of directed and rapid migration along a chemotactic gradient and this phenomenon requires the insertion of new 
membrane mass, via vesicles from the Golgi apparatus, at the region of the cell surface that becomes the leading edge $(14,41)$. Cells that cannot polarize their membrane recycling are generally unable to locomote (14). We suggest that rab protein overexpression in phagocytes could reflect their involvement in each step of the very active process of membrane recycling.

In conclusion, our data suggest that the increased transcription of rab genes could be one aspect of the differentiation program of phagocytes. In addition, the acquisition of wellcharacterized cell functions by maturing phagocytes may render this cell model a useful tool in the understanding of the physiological role of the small G-proteins from the rab family.

\section{Acknowledgments}

We are greatly indebted to Nicolas Touchot, Ahmed Zahraoui, and Armand Tavitian for the gift of rab cDNAs and the recombinant rab proteins. We gratefully acknowledge Brigitte Olofsson for providing the GAPDH probe; Spencer Brown and Dominique Marie for their expert assistance in the cytometry; Eric G. Berger for the gift of the antiserum against galactosyl transferase; and Babette B. Weksler, Armand Tavitian, and Mary McCaffrey for critical reading of the manuscript.

\section{References}

1. Barbacid, M. 1987. Ras genes. Annu. Rev. Biochem. 56:779-827.

2. Burgoyne, R. D. 1989. Small GTP-binding proteins. Trends Biochem. Sci. 14:394-396.

3. Segev, N., J. Mulholland, and D. Botstein. 1988. The yeast GTP-binding YPT1 protein and a mammalian counterpart are associated with the secretion machinery. Cell. 52:915-924.

4. Goud, B., A. Salminen, N. C. Walworth, and P. Novick. 1988. A GTPbinding protein required for secretion rapidly associates with secretory vesicles and the plasma membrane in yeast. Cell. 53:753-768.

5. Novick, P., and R. Schekman. 1983. Export of major cell surface proteins is blocked in yeast secretory mutants. J. Cell Biol. 96:541-547.

6. Zahraoui, A., N. Touchot, P. Chardin, and A. Tavitian. 1989. The human rab genes encode a family of GTP-binding proteins related to yeast YPTI and SEC4 products involved in secretion. J. Biol. Chem. 264:12394-12401.

7. Olofsson, B., P. Chardin, N. Touchot, A. Zahraoui, and A. Tavitian. 1988. Expression of the ras-related ral1, rhol 2 and rab genes in adult mouse tissues. Oncogenes. 3:231-234.

8. Burstein, E., and I. A. Macara. 1989. The ras-like protein p25 ${ }^{\text {mb3A }}$ is partially cytosolic and is expressed only in neural tissue. Mol. Cell. Biol. 9:48074811.

9. Fisher v. Mollard, G., G. A. Mignery, M. Baumert, M. S. Perin, T. J. Hanson, P. M. Burger, R. Jahn, and T. C. Sudhof. 1990. Rab3 is a small GTPbinding protein exclusively localized to synaptic vesicles. Proc. Natl. Acad. Sci. USA. 87:1988-1992.

10. Darchen, F., A. Zahraoui, F. Hammel, M. P. Monteils, A. Tavitian, and D. Scherman. Association of the GTP-binding prot rab3Ap with bovine adrenal chromaffin granules. Proc. Natl. Acad. Sci. USA. In press.

11. Ayala, J., B. Olofsson, A. Tavitian, and A. Prochiantz. 1989. Developmental and regional regulation of rab3, a new brain specific "ras-like" gene. J. Neurosci. Res. 22:241-246.

12. Sano, K., A. Kikucki, Y. Matsui, Y. Teranishi, and Y. Takai. 1989. Tissue specific expression of a novel GTP-binding protein (smg p25A) mRNA and its increase by nerve growth factor and cyclic AMP in rat pheochromocytoma PC-12 cells. Biochem. Biophys. Res. Commun. 158:377-385.

13. Henson, P. M., J. E. Henson, C. Fittschen, G. Kimani, D. L. Bratton, and D. W. H. Riches. 1988. Phagocytic cells: degranulation and secretion. In Inflammation, basic principles and correlates. J. I. Gallin, I. M. Goldstein, and R. Snyderman, editors. Raven Press, New York. 363-390.

14. Singer, S. J., and A. Kupfer. 1986. The directed migration of eukaryotic cells. Annu. Rev. Cell Biol. 2:337-365.

15. Barrowman, M. M., S. Cockroft, and B. D. Gomperts. 1986. Two roles for the guanine nucleotides in the stimulus-secretion sequence of neutrophils. Nature (Lond.). 319:504-507.
16. Quinn, M. T., C. A. Parkos, L. Walker, S. H. Orkin, M. C. Dinauer, and A. J. Jesaitis. 1989. Association of a ras-related protein with cytochrome b of human neutrophils. Nature (Lond.). 342:198-200.

17. Didsbury, J., R. F. Weber, G. M. Bokoch, T. Evans, and R. Snyderman. 1989. rac, a novel ras-related family of proteins that are botulinum toxin substrate. J. Biol. Chem. 264:16378-16382.

18. Harris, P., and P. Ralph. 1985. Human leukemic models of myelomonocytic development: a review of the HL60 and U937 cell lines. J. Leukocyte Biol. 32:407-422.

19. Maridonneau-Parini, I., S. M. Tringale, and A. I. Tauber. 1986. Identification of distinct activation pathways of the human neutrophil NADPH oxidase. J. Immunol. 137:2925-2929.

20. Maridonneau-Parini, I., M. Errasfa, and F. Russo-Marie. 1989. Inhibition of $\mathrm{O}_{2}^{-}$generation by dexamethasone is mimicked by lipocortin I in alveolar macrophages. J. Clin. Invest. 83:1936-1940.

21. Vindelov, L. 1977. Flow microfluorometric analysis of nuclear DNA in cells from solid tumors and cell suspensions. Virchows Arch. 24:227-242.

22. Borregaard, N., J. M. Heiple, E. R. Simons, and R. A. Clark. 1983. Subcellular localization of the b-cytochrome component of the human neutrophil microbicidal oxidase: translocation during activation. J. Cell Biol. 97:52-61.

23. Bradford, M. M. 1976. A rapid and sensitive method for the quantitation of microgram amounts of protein utilizing the principle of protein-dye binding. Anal. Chem. 72:248-254.

24. Avrameas, S. 1969. Coupling of enzyme to proteins with glutaraldehyde. Use of the conjugates for the detection of antigenes and antibodies. Immunochemistry. 6:43-52.

25. Louvard, D., H. Reggio, and G. Warren. 1982. Antibodies to the Golgi complex and the rough endoplasmic reticulum. J. Cell Biol. 92:92-107.

26. Maniatis, T., E. F. Fritsch, and J. Sanbrook. 1982. Molecular Cloning: a Laboratory Manual. Cold Spring Harbor Laboratory, Cold Spring Harbor, NY. 7.19-7.22.

27. Fort, P., L. Marty, M. Piechaczyk, S. El Sabrouty, C. Dani, P. Jeanteur, and J. M. Blanchard. 1985. Various rat adult tissues express only one major mRNA species from the glyceraldehyde 3-phosphate deshydrogenase multigenic family. Nucleic Acid Res. 13:1431-1442.

28. Goud, B., A. Zahraoui, A. Tavitian, and J. Saraste. 1990. Small GTPbinding protein associated with Golgi cisternae. Nature (Lond.). 345:553-556.

29. Bourne, H. 1988. Do GTPase direct membrane traffic in secretion? Cell. 53:669-671.

30. Polakis, P. G., T. Evans, and R. Snyderman. 1989. Multiple chromatographic forms of the formylpeptide chemoattractant receptor and their relationship to GTP-binding proteins. Biochem. Biophys. Res. Commun. 161:276-283.

31. Roberts, P. J., A. R. Cross, O. T. Jones, and A. W. Segal. 1982. Development of cytochrome $b$ and an active oxidase system in association with maturation of a human promyelocytic (HL60) cell line. J. Cell Biol. 95:720-726.

32. Jesaitis, A. J., J. R. Naemura, R. G. Painter, L. A. Sklar, and C. G. Cockrane. 1982. Intracellular localization of $\mathrm{N}$-formyl chemotactic receptor and $\mathrm{Mg}^{++}$dependent ATPase in human granulocytes. Biophys. Biochim. Acta. 719:556-568.

33. Gardner, J. P., D. A. Melnick, and H. L. Malech. 1986. Characterization of the formyl peptide chemotactic receptor appearing at the phagocytic cell surface after exposure to phorbol myristate acetate. J. Immunol. 136:1400-1405.

34. Segal, A. W. 1989. The electron transport chain of the microbicidal oxidase of phagocytic cells and its involvement in the molecular pathology of chronic granulomatous disease. J. Clin. Invest. 83:1785-1793.

35. Haubruck, H. C., C. Disela, P. Wagner, and D. Gallwitz. 1989. The ras-related mouse yptl protein can functionally replace the YPT1 gene product in yeast. EMBO (Eur. Med. Biol. Organ.) J. 8:1427-1432.

36. Baker, D., L. Wuestehube, R. Scheckman, D. Botstein, and N. Segev. 1990. GTP-binding Yptl protein and $\mathrm{Ca}^{2+}$ function independently in a cell-free protein transport. Proc. Natl. Acad. Sci. USA. 87:355-359.

37. Krause, K. H., and P. D. Lew. 1987. Subcellular distribution of $\mathrm{Ca}^{2+}$ pumping sites in human neutrophils. J. Clin. Invest. 80:107-116.

38. Plutner, H., R. Schwaninger, S. Pind, and W. E. Balch. 1990. Synthetic peptides of the rab effector domain inhibit vesicular transport through the secretory pathway. EMBO (Eur. Mol. Biol. Organ.) J. 9:2375-2383.

39. Chavrier, P., R. G. Parton, K. Simons, and M. Zerial. 1990. Localization of low molecular weight GTP-binding proteins in exocytic and endocytic compartments. Cell. 62:317-329.

40. Steinman, R. M., S. E. Brodie, and Z. A. Cohn. 1976. Membrane flow during pinocytosis. A stereological analysis. J. Cell Biol. 68:665-687.

41. Kupfer, A., D. Louvard, and S. J. Singer. 1982. Polarization of the Golgi apparatus and the microtubule organizing center in cultured fibroblats at the edge of an experimental wound. Proc. Natl. Acad. Sci. USA. 79:2603-2607. 